\title{
Characteristics and Causes of Water Seepage on Riverside Tunnel Structure and Control Measures in Sandy Pebble Stratus
}

\author{
Zhang Wenhan ${ }^{1}$, Xu Jianxiao ${ }^{2}$ \\ ${ }^{1}$ Branch of Water and Urban Enginerring, Chengdu Engineering Corporation Limited, Power China, Chengdu, China \\ ${ }^{2}$ Department of Technology, Chengdu Surveying Geotechnical Research Institute Co., LTD. of MCC, Chengdu, China \\ Email address: \\ 420468401@qq.com (Zhang Wenhan), 2448775356@qq.com (Zhang Wenhan)
}

To cite this article:

Zhang Wenhan, Xu Jianxiao. Characteristics and Causes of Water Seepage on Riverside Tunnel Structure and Control Measures in Sandy Pebble Stratus. American Journal of Civil Engineering. Vol. 7, No. 4, 2019, pp. 101-107. doi: 10.11648/j.ajce.20190704.13

Received: July 4, 2019; Accepted: August 21, 2019; Published: August 27, 2019

\begin{abstract}
The water content and permeability of silt and silt strata are significant in cities of Southwest China, and the seepage of underground passages in cities is unavoidable, which affects normal operation. More serious situation may occur when large-scale water gushing phenomenon and obvious structural deformation appears. After long-term and repeated repairs, water cannot be sealed, and even causes surface subsidence and deformation, voids in ground soil, which cause severe social and economic impacts. Loss. Therefore, it is necessary to formulate effective water shutoff measures for specific seepage projects according to local conditions to ensure that groundwater seepage can be effectively solved or controlled. Taking an underground passage in a city as an example, this paper analyses the causes and characteristics of seepage diseases, explores the specific stratum conditions of seepage location and puts forward control measures. Through detection the effectiveness of the implementation of control measures are verified, which provides reference for the treatment of underground seepage in similar strata.
\end{abstract}

Keywords: Sandy Pebble Stratus, Seepage, Control Measures, Grouting

\section{Introduction}

In a city in southwest China, the depth of the tunnel is $1.7 \mathrm{~m}$. The side wall and roof are cast-in-situ reinforced concrete structures with $0.4 \mathrm{~m}$ thickness. The rectangular cross-section and underground structure are two stories with the total height $12.2 \mathrm{~m}$. The tunnel is located in silt, silty sand and pebble strata and is about $500 \mathrm{~m}$ away from the river. Construction has undergone several years ago which has brought great convenience to production and life. At the same time, the seepage and sand gushing of the structure have seriously affected the normal function, especially in silty sand stratum with large water content. Because of the further expansion of structural cracks caused by seepage and sand gushing, the corrosion intensity of the structure material is reduced by groundwater, and the potential safety hazards are greater. For this reason, effective and long-term stable measures should be taken to control the seepage of structure. Scientific waterproofing engineering technology should be studied and adopted according to the environmental conditions of construction site, and reasonable application of technology should be ensured so as to achieve the anticipated effect of waterproofing engineering [1].

In terms of Engineering technology, the estimation and prevention technology of water leakage in open-cut high-speed railway tunnels in water-rich strata has been studied and practiced in different places around the world in recent years.

A. Kamali. [2] used the data required for seepage estimation include geology information such as lithology and stratigraphy, and considering the geometric, mechanic and hydraulic characteristics of discontinuities. Sato, T [3] used Ordinary Portland cement, super-fine Portland cement and liquid-type colloidal silica in Pre-excavation grouting and post-excavation grouting to investigate their performance as counter measures for reducing groundwater inflow at many locations in the shafts and galleries. The results show that pre-excavation grouting successfully attained the target 
hydraulic conductivity of $2 \mathrm{Lu}$ for Ordinary Portland cement and $0.2 \mathrm{Lu}$ for super-fine Portland cement and thus achieved the purpose of waterproofing. Paul J. C. [4] studied the flyash material, though permeable, can be made relatively impermeable by adding cement to it. The test result suggests that mixing of $15 \%$ of cement to the fly ash gives practically the same value of permeability which is found to be in the initial range of the permeability of clay, and can be used safely in earthen embankments for effective seepage control. S. F. $\mathrm{Wu}$ [5] put up a novel biogrouting technique which employs biocement as the basic grouting material. The results show that the seepage rate through the interfaces of the 18 pieces of granite slabs reduced by 1000 folds.

Scholars are constantly committed to the study of structural seepage and its treatment technology in various strata and groundwater conditions [6-10], and new treatment technologies and processes are emerging, which are not described in detail here. However, the seepage problem of underground structures has far form been cured and is still in the exploratory stage.

Overall, The causes and influencing factors of water leakage in highway tunnels and metro tunnels have been analyzed in multi-level and multi-directional ways [11-12]. The influence of unfavorable factors such as groundwater level, structural crack degree and surrounding rock loosening has also been analyzed. The influence of road structure safety [13]. At present, cement grouting, chemical grouting, structural self-waterproofing and membrane waterproofing are commonly used in water-proofing materials, and some application examples of fully sealed waterproofing technology are also given [14]. Taking the seepage control project of underground tunnel structure in a city as an example, this paper provides a method of emergency repair and post-treatment by grouting technology when large area seepage and sand gushing occurs. Therefore, the problem of tunnel seepage in water-rich areas has become a key link in urban construction and should be paid enough attention. If an accident occurs, it will seriously threaten the safety of tunnel and surrounding buildings.

After the preliminary completion of the main structure of the tunnel studied in this paper, a large area of seepage like water and sand gushing occurred, and the whole project could not be put into use for more than three years after the time of completion. Repeated grouting repair has been carried out for up to one year after seepage occurred, but it has not been cured effectively. In view of this, through the analysis of regional hydro geological conditions and tunnel seepage characteristics, the feasible and effective treatment measures for tunnel seepage in water-rich sandy cobble stratum are obtained through practice. The research results can provide reference for the design and construction of seepage prevention and control of underground structures under similar geological conditions.

\section{Site Conditions}

\subsection{Stratigraphic Conditions}

The underground tunnel site of a city is located in the second grade terrace, and the terrace near the river and in the area is well developed, which is $10-12 \mathrm{~m}$ higher than the water surface of the river, and the width of the terrace is about $500-550 \mathrm{~m}$. It belongs to alluvial landform. The main active zones of groundwater are generally concentrated in the shallow part. Q3al sandy gravel layer is the best groundwater in the region, and its water quantity is relatively abundant. The groundwater type is porous diving, which mainly distributes along the river, including river accumulation floodplain and grade I and II terraces. The floodplain is well developed, the thickness of sand and gravel layer varies from $6 \mathrm{~m}$ to $12 \mathrm{~m}$, the permeability is good, and the groundwater is closely related to the river water. The material composition of terraces generally has a relatively complete binary structure, that is, the upper part is silty sand and clayey sand with relatively poor permeability, and the lower part is sandy gravel layer with good permeability. Groundwater table and water content generally fluctuate greatly, with obvious seasonal changes.

According to the drilling data in the field, it is divided from top to bottom into silty clay, silt, silty soil, silty sand and pebble. Among them, the sand-pebble layer has the best water-bearing capacity, larger water volume and the strongest water permeability. It is the main circulation layer of groundwater. The water in the stratum is also the main source of influencing tunnel seepage. The silt and clay layers on the sand-pebble layer are the relative water-resisting layers. The water-rich of each aquifer group is shown in Table 1.

Table 1. Strata and Water Richness Statistical Table in Engineering Area.

\begin{tabular}{|c|c|c|c|}
\hline Srata & Hydro Condition & Water-rich Degree & Distribution Area \\
\hline $\begin{array}{l}\text { miscellaneous fill } \\
\text { silty clay }\end{array}$ & None water & $\begin{array}{l}\text { weak } \\
\text { weak }\end{array}$ & $\begin{array}{l}\text { Exposed thickness } 0.5-6.0 \mathrm{~m} \text {, whole side distributed } \\
\text { thickness } 0.5-6.0 \mathrm{~m} \text {, most side distributed }\end{array}$ \\
\hline $\begin{array}{l}\text { silty soil } \\
\text { silty soil with sand } \\
\text { silt }\end{array}$ & $\begin{array}{l}\text { Pore water, relatively poor, single well water } \\
\text { inflow }<100 t / d\end{array}$ & secondary & $\begin{array}{l}\text { thickness } 2.0-10.7 \mathrm{~m} \text {, local fine sand, most side distributed } \\
\text { thickness } 0.9-9.4 \mathrm{~m} \text {, local fine sand, most side distributed } \\
\text { thickness } 0.6-7.8 \mathrm{~m} \text {, local fine sand, most side distributed }\end{array}$ \\
\hline pebble & $\begin{array}{l}\text { Pore water, relatively rich, single well water } \\
\text { inflow } 100-1000 \mathrm{t} / \mathrm{d}\end{array}$ & rich & thickness $12-18 \mathrm{~m}$, whole side distributed \\
\hline
\end{tabular}

\subsection{Groundwater Recharge, Runoff and Drainage}

Ground water flow conditions in the site are fan-shaped, and the runoff is dispersed from the project area to the river. In the process of runoff, shallow groundwater and surface water exchange and complement each other in the suitable geomorphologic position. The groundwater in the project area is two layers. The upper groundwater is recharged by the 
surrounding domestic water and atmospheric rainfall. It is stored in the filling layer. It has no uniform static water surface and is easy to drain. The groundwater in the lower layer is porous diving with little pressure. The main aquifers are pebble and silt, silt is weak permeable, silty clay is relative aquifer, and it is mainly recharged by atmospheric rainfall, river and lake water. The static groundwater level of silt silt layer is 4-7 $\mathrm{m}$ deep and the stable groundwater level of lower pebble layer is $10-15 \mathrm{~m}$ deep. The groundwater type in the site area is mainly pore water of river deposited sandy pebble layer (Q4al), which is mainly supplied by river water and atmospheric rainfall. A part of the river water will enter the Quaternary alluvium and mainly supply the pebble layer in the area. Therefore, the groundwater quantity in the pebble layer is stable, and the groundwater level in the upper layer varies with the seasons.

\section{Analysis of Seepage Situation and Characteristics}

\subsection{Seepage}

The whole underground tunnel seepage phenomenon is serious, large-scale water and sand gushing mainly concentrated in the original structure deformation joints and construction joints, underground passage water and sand accumulation phenomenon is serious, field investigation found a total of 1828 seepage points. At the same time, the continuous scouring of water takes away the sediment in the surrounding soil of underground engineering, destroys the original structure of surrounding roads and buildings, and even causes surface settlement and deformation. Voids have appeared in many areas. Field deformation diseases are shown in Figure 1.

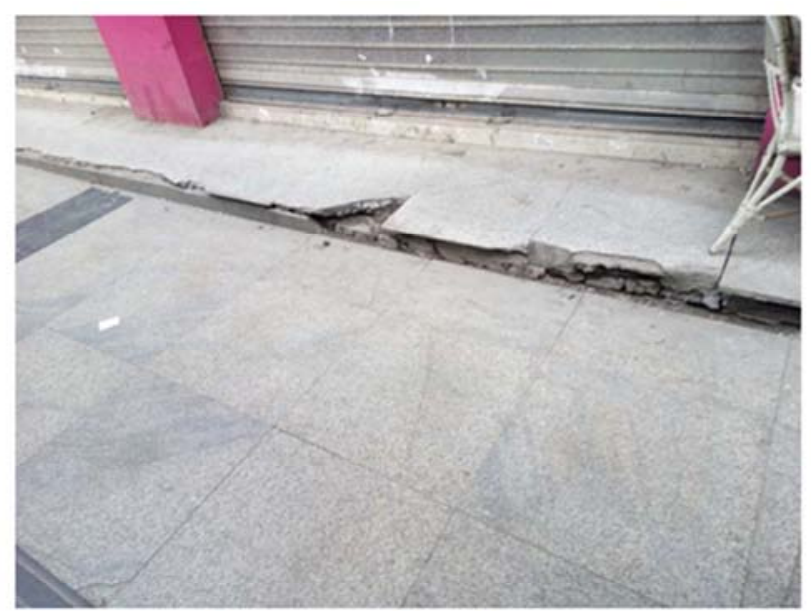

(a) Surface subsidence and crack

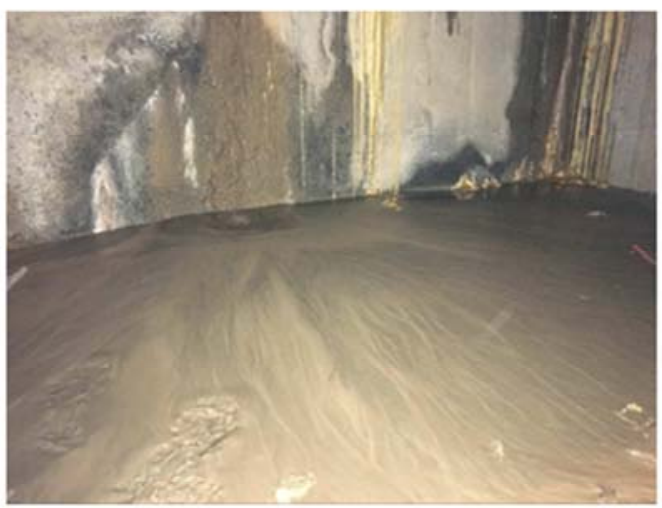

(c) Sand gushing from floor

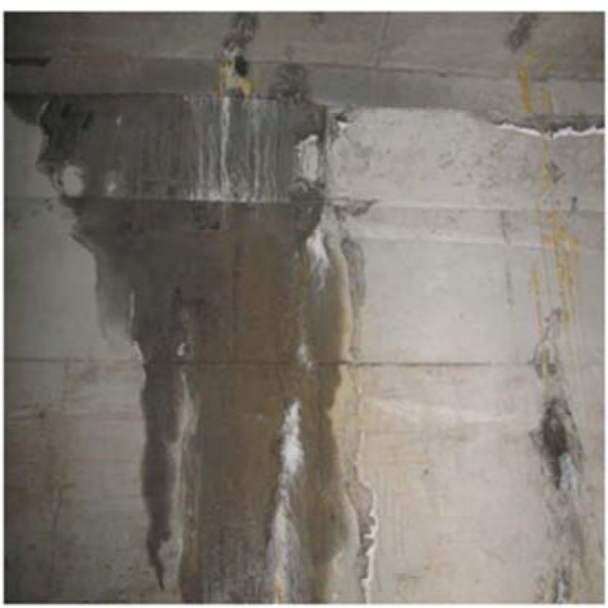

(b) Seepage of sidewall

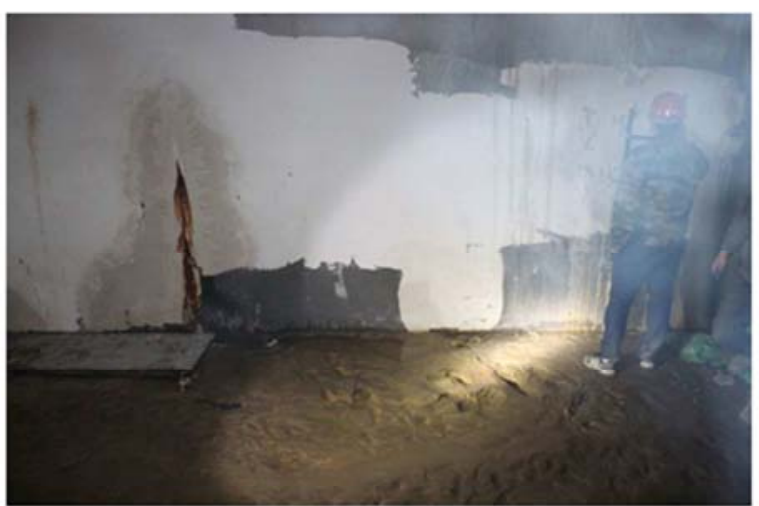

(d) Structural decoration layer seriously damaged

Figure 1. Seepage Photo in site.

\subsection{Characteristic Analysis}

\subsubsection{Seepage Pattern}

According to the field investigation, the crack development of concrete wall and roof conforms to certain rules. The wall surface is a point-like seepage point, vertical and horizontal seepage zone; the plate surface is mainly a band-like seepage crack, which is characterized by developing along the transverse axis, long length and terminating at the column cap (or column bracket) or corner, reflecting the significant characteristics of longitudinal tensile stress; a few cracks are developed along the longitudinal axis and have a shorter length, and the roof and wall surface are classical. Figure 2 shows the distribution of cracks. 


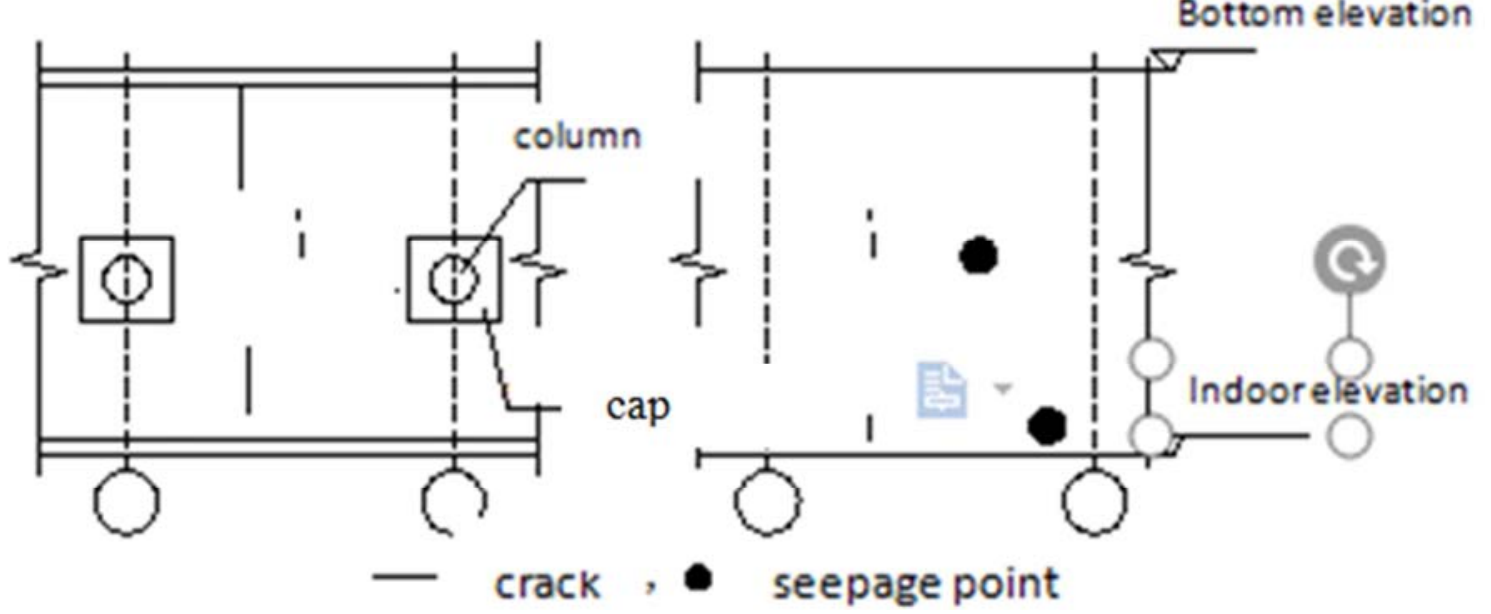

Figure 2. Diagram of typical crack distribution in concrete roof and wall.

\subsubsection{Statistics of Seepage Points}

Statistical analysis of leakage in field investigation shows that side wall leakage is more than roof leakage, $61.7 \%$ of side wall leakage, $38.3 \%$ of roof, floor and corner leakage, $69.3 \%$ of side wall leakage is point leakage, while the point leakage in roof leakage is only $6.7 \%$ of roof leakage, which is far less than the line leakage point of roof. For the whole underground construction project, the number of linear seepage points is more than that of point seepage points, which is nearly $20.5 \%$.

\subsubsection{Seepage}

Seen from the seepage situation, the linear and point seepage of the roof are mainly dripping water, the seepage volume is not large, generally less than $1 \mathrm{ml} / \mathrm{min}$, the maximum seepage point is about $2 \mathrm{ml} / \mathrm{min}$, but some seepage points are relatively concentrated, and the leakage situation is more serious.

Most of the point-like seepage points in the side wall are water seepage, which is only reflected in the wetness of the wall. Although most of the linear seepage points of the side wall also show water seepage, the amount of water seepage is very small, which only makes the wall wet (not affected by rainfall); the water seepage and sand gushing of the side wall mainly occur in some wall cracks (i.e. linear seepage points), with a total seepage flow of $176 \mathrm{ml} / \mathrm{s}$.

\section{Cause Analysis and Prevention Measures}

\subsection{Disease Cause Analysis}

Based on the above analysis, the causes of water seepage and sand gushing under the tunnel are analyzed as follows:

1) The seepage and sand gushing points in underground space are mainly concentrated in the relatively weak parts of the structure, such as structural deformation joints and construction joints, settlement joints and joints. The seepage along the cracks at the roof leads to serious water and sand accumulation in underground passages.
At the same time, according to the data, the waterproofing measures of the project are imperfect, and the inspection results of drilling holes in the side wall show that there are many structural joints and honeycomb holes in the structure. These structural weaknesses are the positions where groundwater is easy to pass through. The weak links provide a channel for groundwater seepage, as shown in Figure 3.
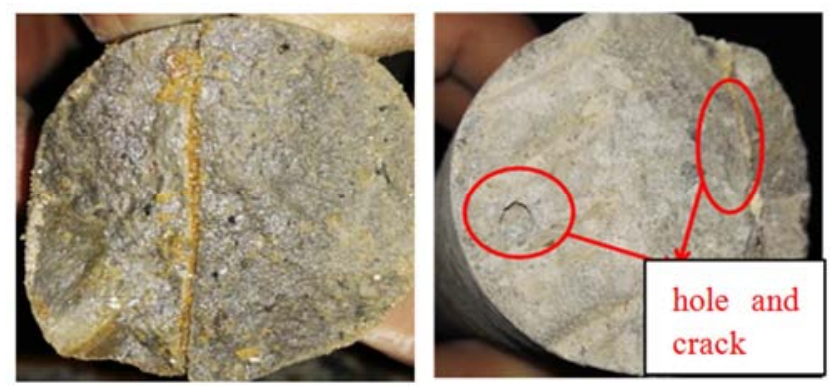

Figure 3. Concrete cracks and holes revealed by sidewall borehole.

2) With the stop of large-scale urban construction (pumping), the groundwater rises again, the water pressure on the side wall of underground engineering increases, which aggravates the seepage deformation of the side wall, which is also one of the main causes of the engineering diseases. The groundwater level ranged from $4.5 \mathrm{~m}$ in 2012 to 2016 . Through the simulation analysis of the underground seepage field in the engineering area, it is known that after the construction of underground passage, because the excavation of rock and soil destroys the stability of the natural seepage field, a catchment area is formed around the underground structure, and the groundwater tends to drain into the underground passage. With the passage of time, the scope of the groundwater falling funnel around the underground structure also tends to expand gradually.

3) Seen from the regional hydrological conditions, the project is located in the area where groundwater is developed. The groundwater types are mainly superficial 
stagnant water, porous diving and bedrock fissure water. According to the analysis, the main sources of leakage water recharge in the side wall and floor of underground structure are the upper layer of sand and pebble layer stagnant water and atmospheric precipitation, municipal water and porous diving, and the roof leakage is greatly affected by atmospheric precipitation and municipal water.

4) Poor soil structure is the internal cause of seepage disease. In the depth range of underground structure of this project, the stratum structure is in turn miscellaneous fill, silty clay, silt, silt and pebble layer from top to bottom. Under the action of long-term seepage, the original structure of rock and soil body is destroyed, fine grained soil is taken away by groundwater, and water and soil mixtures flow out to the parts with large structural fissures through seepage passages formed by long-term seepage, reflecting the seepage and gushing of water at the fissures. Sand phenomenon. With the passage of time, the seepage channels are further enlarged, and large voids are formed in the rock and soil mass, or even surface subsidence and subsidence are caused.

\subsection{Prevention and Control Measures}

\subsubsection{Pre-emergency Management Plan}

According to the field investigation, grouting is mainly used to stop water in the early stage of emergency. The leakage points (including deformation joints) are grouted first, and then flexibly protected by polymer sealing materials, which are mainly used for roof and side walls, as shown in figures 4 and 5. According to the engineering geological conditions and the actual situation of structural seepage, the practical application effects of various grouting materials are compared. In the early stage of grouting, grouting materials including single-liquid foaming water-stop agent, polyurethane water-stop agent and rapid water-stop agent are mainly used. After their interaction with water, the grouting materials can rapidly expand and plug the cracks to achieve the purpose of water-stop.
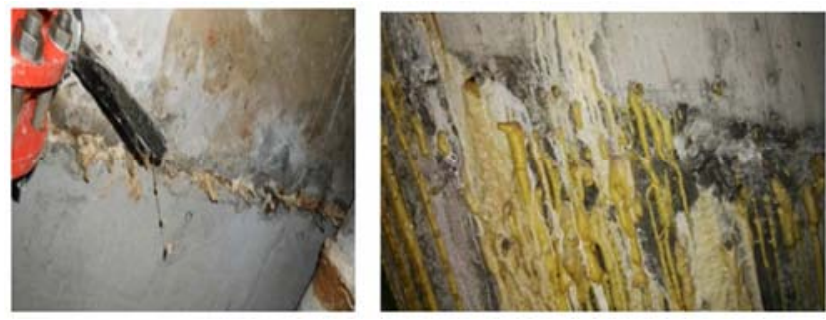

Figure 4. Roof and sidewall grouting.

\subsubsection{Post-treatment Programs and Measures}

According to stratum lithology, scale, type and other characteristics of seepage point, according to relevant construction experience and cases, cement grouting, polyurethane polymer chemical grouting material and SJP grouting material are used to treat different seepage points respectively. The main points of the current emergency plan are as follows:

i. Cement slurry grouting: Cement slurry grouting is used in areas with good formation conditions and no obvious seepage and sand gushing.

ii. Special material grouting: special material grouting is used in areas with poor geotechnical conditions and obvious seepage and sand gushing, different special materials are selected for grouting according seepage form in different parts.

For dripping and seepage on the roof, polyurethane polymer chemical grouting material is used. For seepage, line flow, water gushing on side wall, floor and corner, SJP [15] grouting material is used.

The grouting construction steps are as follows:

1) Grouting hole formation

Select the area with serious seepage and sand gushing, and open the hole in the corresponding position of the side wall (the hole position should be between the retaining piles, see Figure 5). The bottom hole is $30 \mathrm{~cm}$ away from the bottom plate and the borehole inclines 30 degrees downward, so that the silty clay, silt and silty sand with weak plastic-fluid characteristics can be discharged from the bottom hole as much as possible. The hole spacing of replacement grouting is $0.7 \mathrm{~m}$, and the cleaning hole is set in the middle to flush out the replacement space. The flushing hole does not need to be closed.

2) Flushing

When the drilling hole reaches the predetermined hole depth, the drilling tool is lowered to the bottom of the hole and flushed with a flow rate of not less than $35 \mathrm{~m} / \mathrm{s}$ and not more than $50 \mathrm{~m} / \mathrm{s}$ in principle. The other holes are opened until the water-sand mixture flows out from the other holes and passes through. Then the intermediate holes are replaced as flushing holes until the water and sand flow out of the other holes and the sand content in the outflow water is lowest or lowest. Clean water will eventually flow out, that is, the rinse is completed.

\section{3) Grouting}

Start grouting, the other holes open until the cement slurry flows out of the other holes, and when the slurry reaches the water cement ratio at the time of preparation, close the hole and continue to inject the cement slurry. The grouting pressure should not be less than $0.5 \mathrm{MPa}$. When the grouting quantity reaches the design value, or when the grouting time exceeds the pumpable period of the grout, the grouting can be terminated; when the design pressure is reached, the grouting quantity is not more than $10 \mathrm{~L} / \mathrm{min}$ and the grouting can be maintained for 10 minutes, the grouting can be terminated.

\subsection{Governance Effect}

For some point-like seepage with large water leakage, cement-water glass double-liquid grouting or pure cement grouting are used directly, mainly for the lower side wall, corner and floor. The results of seepage grouting in the early stage were analyzed and analyzed. The treatment rate of seepage point is $97.4 \%$, and the successful treatment rate is $47.8 \%$. The seepage points investigated by side walls were all 
treated successfully, accounting for $29.6 \%$. The treatment rate of roof is $95.1 \%$, and the treatment effect is better than that of

side walls, with a success rate of $64.7 \%$.

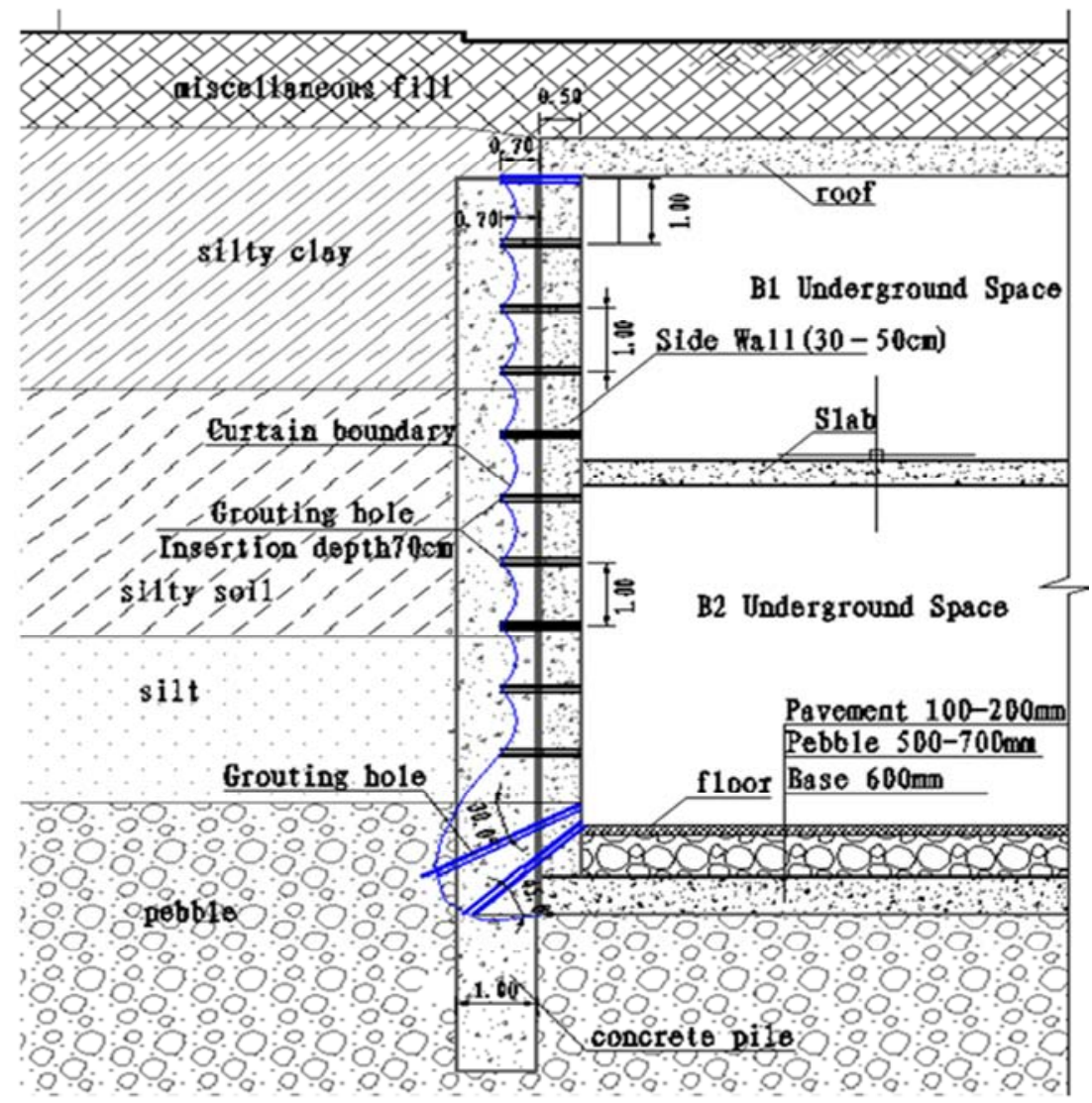

Figure 5. Layout of sidewall grouting holes.

However, the early rescue still has some failures, the reasons are as follows:

1) Many external structural cracks and internal pore channels are the main causes of partial failure. For example, cracks caused by super-long structure, invisible passages and cracks caused by quality defects of local construction and pouring of concrete, local concrete is not compact, and in the process of grouting, the slurry fails to effectively condense in the cracks of concrete to form a certain strength stone body, which is characterized by relatively loose and porous cracks.

2) The inappropriate construction procedure and inadequate construction measures in the pre-grouting construction are also the reasons for the failure of the pre-emergency part. After waterproof and leak-stopping grouting, all grouting pipes should be cut off, the interface should be dried and cleaned, and a semi-rigid protective layer should be constructed. Even if the crack no longer leaks, the strength of the structure has not been improved, resulting in some interfaces still seepage after treatment.

Later grouting treatment is mainly aimed at seepage or serious sand gushing. Side wall water gushing is columnar with a diameter of about $3 \mathrm{~cm}$. At the same time, the water quality is turbid and contains silt. This treatment method has successfully stopped water and blocked sand gushing without recurrence. As shown in Figure 5, it proves that the grouting treatment measures under the hydrogeological conditions of this project are effective.

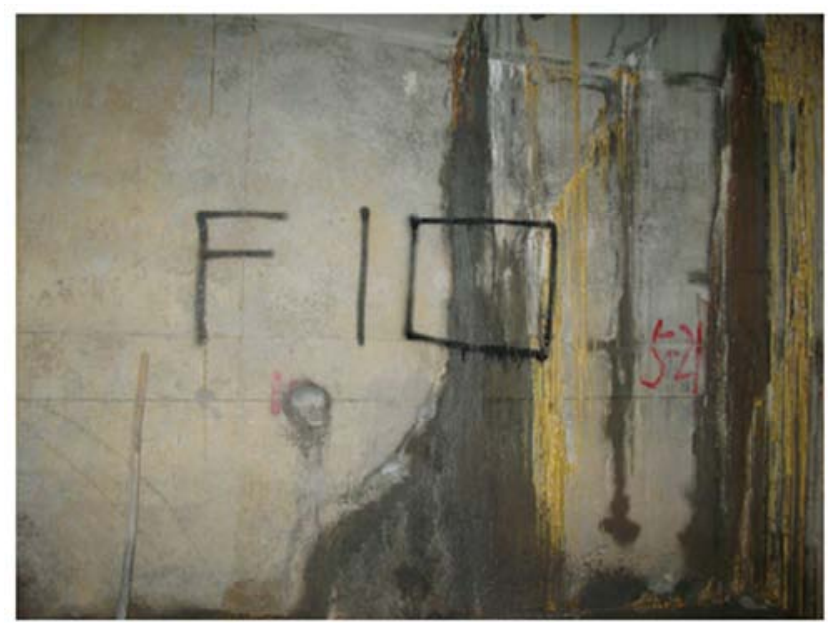

Figure 6. Effect of sand gushing treatment.

\section{Conclusion}

Based on the investigation results of tunnel seepage in sandy gravel stratum, the causes and prevention measures of tunnel seepage are studied, and the following conclusions are 
drawn:

1) The seepage points of Underpass tunnels mainly concentrate on the relatively weak parts of structures such as structural deformation joints and construction joints, settlement joints and joints. The weak links provide a channel for groundwater seepage.

2) The catchment area is formed around the underpass tunnel, and the groundwater has the tendency of draining to the underground passage. With the passage of time, the scope of the falling funnel of the groundwater around the underground structure has the tendency of gradually expanding, which results in the increase of the water pressure on the side wall of the underpass tunnel and provides the hydraulic conditions for the leakage of water.

3) The project is located in an area where groundwater is developed. The main types of groundwater are superficial stagnant water, porous diving and bedrock fissure water. Complex hydrogeological conditions directly promote the occurrence of water seepage diseases.

4) It is suggested to adopt the principle of combining geotechnical seepage control with structural waterproofing. The treatment measures should be considered according to the engineering geological conditions, the zoning of deformation characteristics and the subsection.

Because the tunnel seepage disease is often not the result of a cause, but the result of a variety of reasons, it is often difficult to accurately infer the real cause of the seepage disease in many cases, but the author summarizes several main reasons based on the survey results, which can provide reference for the design and construction of the tunnel seepage disease prevention and control project.

\section{References}

[1] Research on waterproofing engineering technology for construction projects [J] (in Chinese). New Chinese technologies and products. 2018 (10): 123-125.

[2] A. Kamali, K. Shahriar, M. El Tani, A. Aalianvari, M. A. Gholami. Challenging estimation of seepage in powerhouse cavern and drainage tunnel in Iran [C]. Geomechanics and Geodynamics of Rock Masses - Volume 2 Proceedings of the 2018 European Rock Mechanics Symposium.

[3] T. Sato, S. Mikake S. Kobayashi, M. Tsuji. Status of Grouting to Reduce Groundwater Inflow into Deep Shafts and Galleries in the Mizunami Underground Research Laboratory, Japan ISRM International Symposium - 8th Asian Rock Mechanics Symposium, 2014.
[4] Paul J. C., Panigrahi B. Study of Seepage Control and Strength Characteristics of Fly Ash in Earthen Embankments [J]. Agricultural Engineering Today 2018, 42 (4): 65-71.

[5] S. F. Wu, J. Chu, C. Z. Wu. Biogrouting for Seepage Control for Rock Joints (C). ISRM International Symposium-10th Asian Rock Mechanics Symposium, 29 October - 3 November, Singapore, 2018.

[6] Mohamed El Tani, Abbas Kamali, Mohamed Ali Gholami. Analytic Assessment of the Water Table Drawdown, Seepage, and Back Pressure at Rudbar PSPPRock [J]. Mechanics and Rock Engineering, 2019, 52 (7): 2227-2243.

[7] Jinquan Liu, Weizhong Chen, Jingqiang Yuan, Changjun Li, Qingyan Zhang, Xiaofei Li. Groundwater control and curtain grouting for tunnel construction in completely weathered granite $[\mathrm{J}]$. Bulletin of Engineering Geology and the Environment, 2018, 77 (2): 15-531.

[8] Gang Zhou, Wen-jing Yin, Xing Wei. Numerical Simulations on the Low-Pressure Water-Injection-Induced Seepage Rules of Coal with Pre-existing Plane/Surface Fractures [J]. Geotechnical and Geological Engineering, 2019, 37 (4): 3283-3297.

[9] Mustafa Chouireb, AbdelkaderDjehiche. Simulation of seepage flow through an earthen dam with vertical drain and comparison of results with observations data (case study: Harreza dam-Algeria) [J] Arabian Journal of Geosciences, 2019, 12 (13): 1-7.

[10] Dong-mei Zhang, Zi-sheng Liu, Ru-lu Wang, Dong-ming Zhang. Influence of grouting on rehabilitation of an over-deformed operating shield tunnel lining in soft clay $[\mathrm{J}]$. Acta Geotechnica, 2019, Vol. 14 (4), pp. 1227-1247.

[11] Zou Yulin, He Chuan, Zhou Yi, Zhang Zheng, Fu Jiakun. Statistical analysis and causes of seepage diseases in existing operating tunnels of Chongqing Expressway [J] (in Chinese). Highway Transportation Science and Technology, 2013, 30 (01): 86-93+101.

[12] Shi Jianxun, Liu Xinrong, Cao Wanzhi, Chen Chengqin, Yang Yongheng. Evaluating the influencing factors of seepage disease in multi-arch tunnel by improved AHP [J] (in Chinese). Progress in geophysics, 2013, 28 (01): 482-487.

[13] Wang Wei, Zhao Dong, Gui Fengtao. Study on the safety of railway tunnel lining structure under water leakage $[\mathrm{J}]$ (in Chinese). Chinese Journal of Safety Sciences, 2016, 26 (06): $86-90$

[14] Fully Sealed Waterproofing Technology for Urban Underground Comprehensive Pipeline Gallery [J] (in Chinese). Journal of Underground Space and Engineering. 2018 (S1): 6-11.

[15] Xiangjun Pei, Wenchen Wang, Junge Xie, Jiaxing, Zhang, Yang Fuquan, Ye Du. Study on Controllable Grouting Technology of SJP Cement Slurry for Sealing Strong Water Gushing Borehole [J]. (in Chinese). Exploration Engineering (Rock \& Soil Drilling and Tunneling) 2017.05: 62-67. 